\title{
Anomalous Thermal Characteristics of Poly(ionic liquids) Derived from 1-Butyl-2,3-dimethyl-4-vinylimidazolium Salts
}

\author{
Fan Yang ${ }^{1}$, Meng Zhao ${ }^{2}$, Darren Smith ${ }^{3} \mathbb{D}$, Peggy Cebe $^{4}\left(\mathbb{D}\right.$, Sam Lucisano ${ }^{5}$, Thomas Allston ${ }^{6}$ and \\ Thomas W. Smith ${ }^{6, *}$ \\ Versick Analytics, Jersey City, NJ 07310, USA; yangf0530@gmail.com \\ BOE Technology Group, Beijing 100176, China; 15101035632@139.com \\ Walter Reed Army Institute of Research, Silver Spring, MD 20910, USA; darren.m.smith37.mil@mail.mil \\ Physics and Astronomy Department, Tufts University, Medford, MA 02155, USA; Peggy.Cebe@tufts.edu \\ $5 \quad$ Xerox Corporation, Webster, NY 14580, USA; slucisano2387@gmail.com \\ 6 School of Chemistry \& Materials Science, Rochester Institute of Technology, Rochester, NY 14623, USA; \\ tdasch@rit.edu \\ * Correspondence: twssch@rit.edu
}

check for updates

Citation: Yang, F.; Zhao, M.; Smith, D.; Cebe, P.; Lucisano, S.; Allston, T.; Smith, T.W. Anomalous Thermal Characteristics of Poly(ionic liquids) Derived from 1-Butyl-2,3-dimethyl-4vinylimidazolium Salts. Polymers 2022, 14, 254. https://doi.org/ $10.3390 /$ polym 14020254

Academic Editor: Jason Bara

Received: 15 December 2021

Accepted: 5 January 2022

Published: 8 January 2022

Publisher's Note: MDPI stays neutral with regard to jurisdictional claims in published maps and institutional affiliations.

Copyright: (C) 2022 by the authors. Licensee MDPI, Basel, Switzerland. This article is an open access article distributed under the terms and conditions of the Creative Commons Attribution (CC BY) license (https:// creativecommons.org/licenses/by/ $4.0 /)$

Abstract: The synthesis of 1-butyl-2,3-dimethyl-4-vinylimidazolium triflate, its polymerization, and ion exchange to yield a trio of 1-butyl-2,3-dimethyl-4-vinylimidazolium polymers is described. Irrespective of the nature of the anion, substitution at the 2-position of the imidazolium moiety substantially increases the distance between the anion and cation. The methyl substituent at the 2-position also served to expose the importance of $\mathrm{H}$-bonding for the attractive potential between imidazolium moiety and anions in polymers without a methyl group at the 2-position. The thermal characteristics of poly(1-butyl-2,3-dimethyl-4-vinylimidazolium) salts and corresponding poly(1ethyl-3-methyl-4-vinylimidazolium) salts were evaluated. While the mid-point glass transition temperatures, $\mathrm{T}_{\mathrm{g}}$-mid, for 1-ethyl-3-methyl-4-vinylimidazolium polymers with $\mathrm{CF}_{3} \mathrm{SO}_{3}{ }^{-},\left(\mathrm{CF}_{3} \mathrm{SO}_{2}\right)_{2} \mathrm{~N}^{-}$ and $\mathrm{PF}_{6}{ }^{-}$counterions, were $153{ }^{\circ} \mathrm{C}, 88^{\circ} \mathrm{C}$ and $200{ }^{\circ} \mathrm{C}$, respectively, the $\mathrm{T}_{\mathrm{g}}$-mid values for 1-butyl-2,3dimethyl-4vinylimidazolium polymers with corresponding counter-ions were tightly clustered at $98^{\circ} \mathrm{C}, 99^{\circ} \mathrm{C}$ and $84{ }^{\circ} \mathrm{C}$, respectively. This dramatically reduced influence of the anion type on the glass transition temperature was attributed to the increased distance between the center of the anions and cations in the 1-butyl-2,3-dimethyl-4-vinylimidazolium polymer set, and minimal H-bonding interactions between the respective anions and the 1-butyl-2,3-dimethyl-4-vinylimidazolium moiety. It is believed that this is the first observation of substantial independence of the glass transition of an ionic polymer on the nature of its counterion.

Keywords: poly(ionic liquids); ionic liquid polymer; thermal analysis; ion-conductive polymer; vinylimidazolium monomers; ionic liquids

\section{Introduction}

Ionic liquids are salts with low melting points (often below room temperature) and are typically composed of sulfonium, phosphonium, or ammonium (imidazolium, pyridinium, pyrrolidinium) cations paired with anions of low Lewis basicity (tetrafluoroborate $\left(\mathrm{BF}_{4}{ }^{-}\right)$, hexafluorophosphate $\left(\mathrm{PF}_{6}^{-}\right)$, triflate $\left(\mathrm{Tf}^{-}\right)$, trifluoromethylsulfonylimide (TFSI $\left.{ }^{-}\right)$, etc.). Today, the utility of ionic liquids in electrochemical devices [1,2] ranging from lithium-ion batteries [3,4] to fuel cells [5,6], capacitors [7,8], solar cells $[9,10]$ and actuators [11], is being actively explored. Because of the mobility of both the anionic and cationic components of ionic liquids, the function of some devices might be improved if conventional ionic liquids are replaced by film-forming ionic liquid/polymer gel electrolytes or ionic liquid polymers in which the mobility of one or both ions is constrained.

Among poly(ionic liquids), 1-vinylimidazolium polymers were studied most extensively. A 2013 paper by Long et al. [12] that reports on the synthesis, ionic conductivity 
and thermal properties (glass transition temperature, $\mathrm{T}_{\mathrm{g}}$, and thermal stability) of a series of 3-alkyl-1-vinylimidazolium polymer salts $\left(\mathrm{Br}^{-}, \mathrm{BF}_{4}{ }^{-}, \mathrm{Tf}^{-}\right.$, and $\left.\mathrm{TFSI}^{-}\right)$, also provides a concise reference trail that is inclusive of much of the published work on vinylimidazolium polymers [13-26]. In the paper by Long et al. [12], the glass transition temperature of poly(3alkyl-1-vinylimidazolium) salts, regardless of the alkyl substituent length, was reported to decrease as the anion size increased. Specifically, it was reported that the glass transition temperatures of $\mathrm{Br}^{-}, \mathrm{BF}_{4}{ }^{-}, \mathrm{Tf}^{-}$, and $\mathrm{TFSI}^{-}$salts of the 3-ethyl-1-vinylimidazolium polymer $\left(\mathrm{PEVIm}^{+}\right)$were $217,181,145$ and $56^{\circ} \mathrm{C}$, respectively. Similarly, the reported glass transition temperatures of $\mathrm{Br}^{-}, \mathrm{BF}_{4}{ }^{-}, \mathrm{Tf}^{-}$, and $\mathrm{TFSI}^{-}$salts of the 3-butyl-1-vinylimidazolium polymer $\left(\mathrm{PBVIm}^{+}\right)$were $192,148,134$, and $48{ }^{\circ} \mathrm{C}$, respectively. Vygodskii et al. [27] found that the glass transition temperature of $\mathrm{PEVIm}^{+}$salts was $19{ }^{\circ} \mathrm{C}$ when the counterion was $(\mathrm{CN})_{2} \mathrm{~N}^{-}, 60{ }^{\circ} \mathrm{C}$ for $\left(\mathrm{CF}_{3} \mathrm{SO}_{2}\right)_{2} \mathrm{~N}^{-}, 173{ }^{\circ} \mathrm{C}$ for $\mathrm{CF}_{3} \mathrm{SO}_{3}{ }^{-}$and $235^{\circ} \mathrm{C}$ for $\mathrm{Br}^{-}$. Elabd and co-workers [15] investigated the glass transition temperatures and conductivities of poly(1-(2-methacryloyloxy)ethyl-3-butylimidazolium) salts and reported that the glass transition temperatures of $\mathrm{Br}^{-}, \mathrm{BF}_{4}^{-}, \mathrm{PF}_{6}^{-}, \mathrm{Tf}^{-}$, and $\mathrm{TFSI}^{-}$salts were $102,85,94,64$ and $7{ }^{\circ} \mathrm{C}$, respectively. In all of these reports, the glass transition temperature was found to exhibit a significant dependence on the nature of the anion. Colby et al. [28] plotted the glass transition temperature and repeat unit molecular volume of imidazolium-based polyionic liquids, PILs, with a variety of different counterions and observed an ostensibly exponential decrease in $\mathrm{T}_{\mathrm{g}}$ with increasing molecular volume. More recently, Bocharova and Sokolov, et al. reported that the glass transition in poly(ionic liquids) does not scale simply with the volume of structural units (monomer and counterion) and proposed an empirical model that includes electrostatic interactions and chain flexibility to describe $T_{g}$ in ionic liquid polymers [29]. Decoupling of ion transport from segmental mobility was also proposed as a mechanism for the realization of enhanced ion conductivity [30-32].

In our research, we focused on 4-vinylimidazolium polymers [33]. The molecular structure of a pentad segment of a 4-vinylimidazolium polymer is shown in Figure 1.

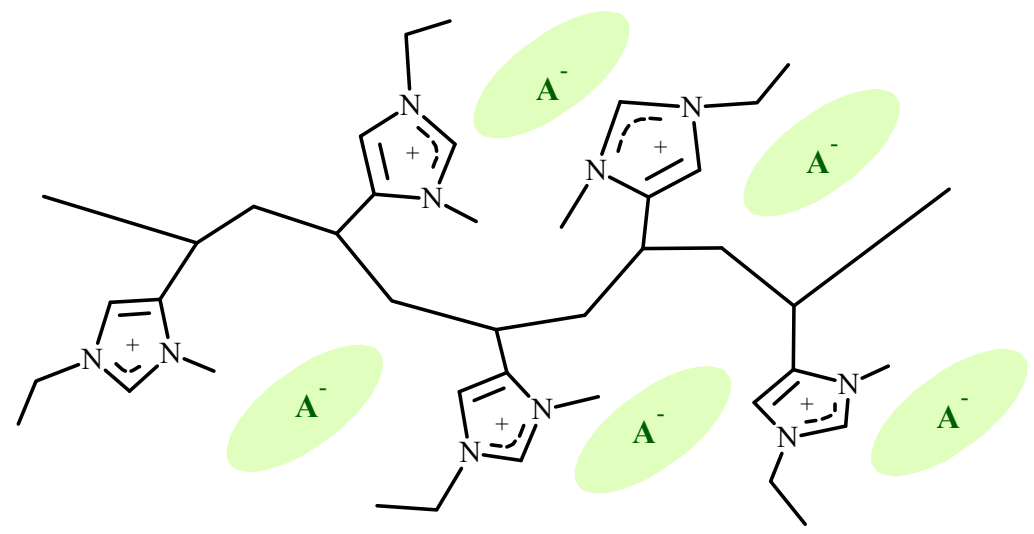

Figure 1. Pentad segment of a 1-ethyl-3-methyl-4-vinylimidazolium polymer.

As compared to the more widely studied 1-vinylimidazolium polymers [12-26,34-37], the pendant imidazolium group in 4-vinylimidazolium polymers can exhibit additional degrees of freedom, increased free volume, and enhanced lateral overlap between proximate imidazolium residues that may be situated 1,3 or 1,5 with respect to each other on the carbon chain. Work from our laboratory on the synthesis, thermal characteristics, and dielectric properties of poly(ionic liquids) derived from 1,3-dialkyl-4-vinylimidazolium salts presented data on the comparative thermal and dielectric characteristics of the 4-vinyl and 1-vinylimidazolium salts [33]. In that work, it was shown that the glass transition characteristics of 4-vinyl- and 1-vinylimidazolium salts are similar, with the glass transition temperatures of $\mathrm{P} 4 \mathrm{VIm}^{+}$[poly(1-ethyl-3-methyl-4-vinylimidazolium)], $\mathrm{BF}_{4}{ }^{-}, \mathrm{PF}_{6}{ }^{-}, \mathrm{AsF}_{6}{ }^{-}$, and $\mathrm{Tf}^{-}$salts being higher than those of the corresponding poly(1-vinylimidazolium) salts. This difference, and the increase in $\mathrm{T}_{\mathrm{g}}$ of $\mathrm{P} \mathrm{VIm}^{+}$salts of complex fluoride ions 
of increasing size $\left(\mathrm{BF}_{4}{ }^{-}, \mathrm{PF}_{6}{ }^{-}\right.$, and $\left.\mathrm{AsF}_{6}{ }^{-}\right)$, was attributed to enhanced intramolecular bridging between imidazolium moieties positioned 1,3 or 1,5 along the 4 -vinylimidazolium polymer chain. The glass transitions of the 1-vinyl- and 4-vinylimidazolium polymers with TFSI $^{-}$and $\mathrm{C}_{2} \mathrm{~N}_{3}{ }^{-}$anions exhibited the lowest glass transition temperatures. The lower glass transition temperatures of the TFSI ${ }^{-}$and $\mathrm{C}_{2} \mathrm{~N}_{3}{ }^{-}$salts were attributed to plasticization by large solvating anions, and the soft nucleophilic character of these anions allows for the association between the anion and cation over a larger distance.

In 1-vinyl- and 4-vinyl-imidazolium polymers, the hydrogen atom at the 2-position of the imidazole ring is somewhat acidic $\left(\mathrm{p} K_{a}=21-23\right)[38,39]$. This acidic character can be the source of chemical and electrochemical instability [40]. In 2-methylimidazolium moieties, the problem is mitigated [41]. This paper describes the synthesis and polymerization of 1-butyl-2,3-dimethyl-4-vinylimidazolium triflate $\left(2,3 \mathrm{DM} 4 \mathrm{VIm}^{+} \mathrm{Tf}^{-}\right)$(see Figure 2 ) and the thermal properties of polymers derived therefrom.<smiles></smiles>

Figure 2. Structure of poly(1-butyl-2,3-dimethyl-4-vinylimidazolium triflate).

\section{Materials and Methods}

\subsection{NMR}

${ }^{1} \mathrm{H}-\mathrm{NMR}$ and ${ }^{19} \mathrm{~F}-\mathrm{NMR}$ spectra were obtained using a Bruker DRX-300 spectrometer and a Brucker Advance III 500 spectrometer, respectively. Monomeric samples were dissolved in chloroform-d (Aldrich, St. Louis, MO, USA 99.8 atom \% D, 0.05\% v/v TMS) or methanol-d4 (Aldrich, St. Louis, MO, USA, 99.96 atom \% D). Polymers were dissolved in dimethylsulfoxide-d6 (ACROS Organics, Geel, Belgium, 99.9 atom \% D). The ${ }^{19} \mathrm{~F}$ nmR spectrum of poly(1-butyl-2,3-dimethyl-4-vinylimidazolium triflate) shows a single sharp peak at $\sim 78 \mathrm{ppm}$. When fully ion-exchanged to poly(1-butyl-2,3-dimethyl-4-vinylimidazolium hexafluorophosphate), no trace of a peak at $\sim 78 \mathrm{ppm}$ is observed, as it is replaced by a doublet centered at $\sim 75 \mathrm{ppm}$ with a coupling constant of about $711 \mathrm{~Hz}$. This splitting arises by virtue of coupling between ${ }^{19} \mathrm{~F}$ and ${ }^{31} \mathrm{P}$. These spectra are included in the Supplementary Information.

\subsection{Thermal Analysis}

Thermal gravimetry (TG) was carried out under a nitrogen atmosphere with a TA Instruments TGA 2050. The temperature was increased from $25-600{ }^{\circ} \mathrm{C}$ at $20{ }^{\circ} \mathrm{C} / \mathrm{min}$, and then held at $600^{\circ} \mathrm{C}$ for $10 \mathrm{~min}$ in air. The thermal stabilities of the triflate and TFSI ${ }^{-}$ salts are similar. Significant mass loss in the TFSI ${ }^{-}$salt occurs between 430 and $505^{\circ} \mathrm{C}$; that in the triflate salt occurs between 440 and $505^{\circ} \mathrm{C}$. TGA mass loss profiles for triflate and TFSI $^{-}$salts of 1-butyl-2,3-dimethyl-4-vinylimidazolium polymers are provided in the Supplementary Information.

Glass transition $\left(\mathrm{T}_{\mathrm{g}}\right)$ data were obtained under a nitrogen atmosphere by differential scanning calorimetry (DSC) using a TA Instruments DSC 2010 with refrigerated cooling system. All samples were prepared in an Ar-filled glove box. Polymer samples were placed in an open, hermetically sealable aluminum pan and heated at $100{ }^{\circ} \mathrm{C}$ for $15 \mathrm{~min}$ on the surface of a digital hot plate in the glove box. The aluminum pan was then capped and 
sealed. In the DSC, samples were ramped to $200{ }^{\circ} \mathrm{C}$ and then cooled to $-50{ }^{\circ} \mathrm{C}$ at a rate of $20^{\circ} \mathrm{C} / \mathrm{min}$. Between each heating and cooling cycle, samples were held for $1 \mathrm{~min}$ at $-50{ }^{\circ} \mathrm{C}$ and $200{ }^{\circ} \mathrm{C}$, respectively. $\mathrm{T}_{\mathrm{g}}$ values are reported as mid-point glass transition temperatures, $\mathrm{T}_{\mathrm{g}}$-mid. The analysis was a seven-step process: (1) heating from $22^{\circ} \mathrm{C}$ to $200{ }^{\circ} \mathrm{C}$ at $20{ }^{\circ} \mathrm{C} / \mathrm{min}$; (2) holding for $1 \mathrm{~min}$ at $200{ }^{\circ} \mathrm{C}$; (3) cooling from 200 to $-50{ }^{\circ} \mathrm{C}$ at $20^{\circ} \mathrm{C} / \mathrm{min}$; (4) holding for $1 \mathrm{~min}$ at $-50{ }^{\circ} \mathrm{C}$; (5) heating from $-50{ }^{\circ} \mathrm{C}$ to $200^{\circ} \mathrm{C}$ at $20{ }^{\circ} \mathrm{C} / \mathrm{min}$; (6) holding for $1 \mathrm{~min}$ at $200{ }^{\circ} \mathrm{C}$; and (7) cooling from $200{ }^{\circ} \mathrm{C}$ to $-50{ }^{\circ} \mathrm{C}$ at $20{ }^{\circ} \mathrm{C} / \mathrm{min}$. The respective polymers were subjected to at least four heating and cooling cycles and results showed that the second and third heating cycles were essentially identical to each other. Second-cycle DSC thermograms for the triflate polymer are shown in Figure 3, where plots of change in heat flow rate in $20^{\circ} \mathrm{C} / \mathrm{min}$ heating and cooling cycles are also shown. An auxiliary $40^{\circ} \mathrm{C} / \mathrm{min}$ rapid heating cycle, which served to validate the change in heat capacity at the glass transition [42], is included in Figure 3.

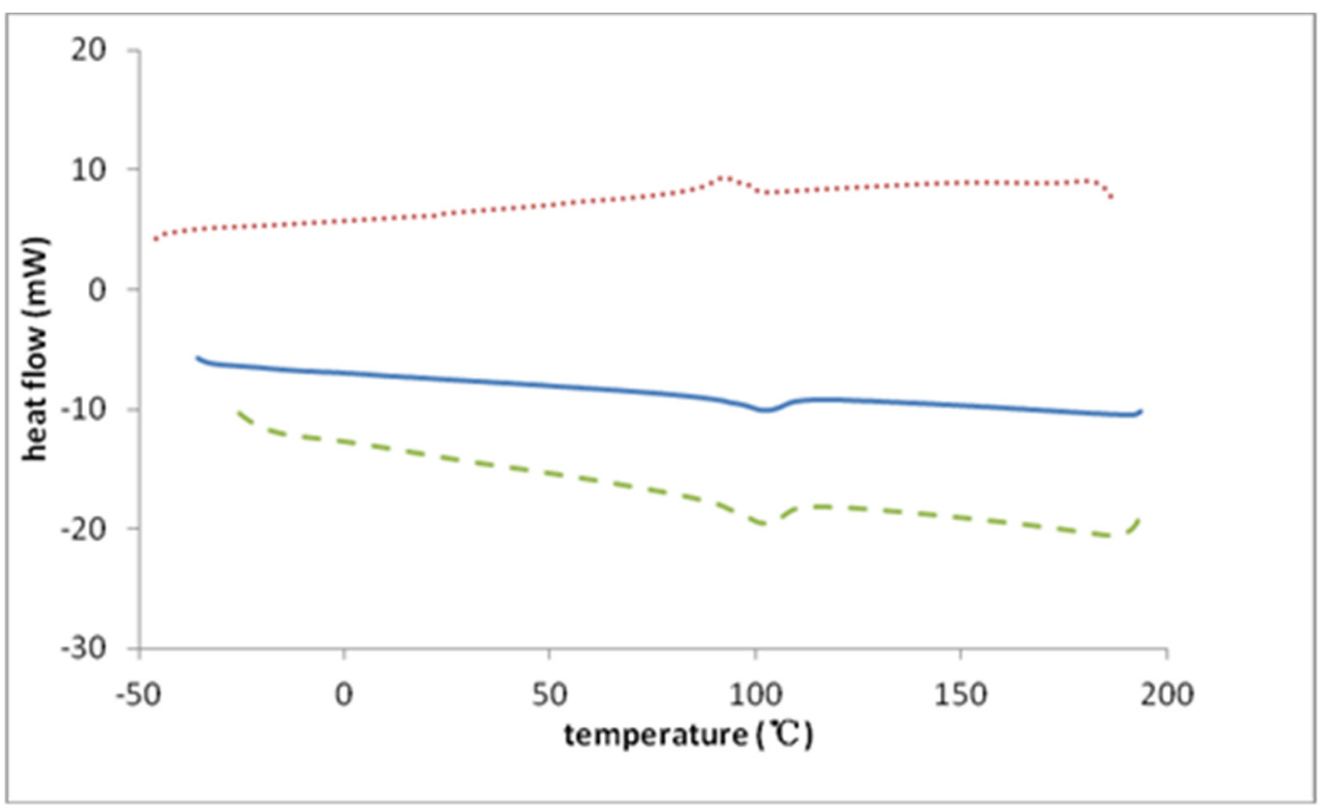

Figure 3. DSC scans for P23DM4VIm ${ }^{+} \mathrm{Tf}^{-}$: solid blue line $\left(20^{\circ} \mathrm{C} / \mathrm{min}\right.$ - heating cycle $)$, dotted red line $\left(20^{\circ} \mathrm{C} / \mathrm{min}\right.$ - cooling cycle $)$, dashed green line $\left(40^{\circ} \mathrm{C} / \mathrm{min}\right.$-rapid heating cycle). Endothermic heat flow is indicated by downward deflection from the baseline.

\subsection{Size Exclusion Chromatography}

Molecular weight and polydispersity were determined using an Agilent (Santa Clara, CA, USA) 1100 series gel permeation chromatograph with two Agilent Zorbax PSM 60$\mathrm{S}$ columns (in series) (Santa Clara, CA, USA). The samples were eluted at $35^{\circ} \mathrm{C}$ using $\mathrm{N}, \mathrm{N}$-dimethylformamide as the solvent. Molecular weight values reported are styreneequivalent molecular weights based on hydrodynamic radii.

\subsection{Reagents}

Unless noted otherwise, all intermediates and reagents purchased from chemical supply houses were used as received. Urocanic acid (4-imidazole acrylic acid, 99\%), butyl lithium (1.6M solution in hexane), sec-butyl lithium (1.4 M solution in cyclohexane), 1,1,1,3,3,3-hexamethyldisilazane (99.9\%), N,N-Dimethylformamide (anhydrous, 99.8\%), benzene (anhydrous, 99.8\%), 1-bromobutane (99\%), methyl trifluoromethanesulfonate ( $\geq 98 \%$ ), bis(trifluoromethane) sulfonimide lithium salt, dimethylsulfoxide (99.6+\%), ammonium hexafluorophosphate (99.99\%), and 2,2'-azobisisobutyronitrile (AIBN, 98\%) were obtained from Sigma-Aldrich (St. Louis, MO, USA). The latter was recrystallized from methanol prior to use. The chemicals 4-tert-Butylcatechol (99\%), potassium tert-butoxide (1 M solution in THF, AcroSeal), triphenylmethyl chloride (98\%), iodomethane (stabilized, 
99\%), methyl alcohol (reagent ACS, 99.8\%), tetrahydrofuran (stabilized, 99+ \%), ethanol ( $95 \%$, denatured with 5\% wood spirit), potassium carbonate (anhydrous, ACS reagent grade), ammonium sulfate, and sodium bicarbonate (ACS reagent grade) were obtained from ACROS Organics (Waltham, MA, USA). Ethyl acetate (AR ACS, 99.5\%), hydrochloric acid (AR ACS), chloroform (AR ACS) and dichloromethane (AR ACS) were obtained from Mallinckrodt Chemicals (Dublin, Ireland). Diethyl ether (anhydrous) and acetone (certified ACS) were obtained from Fisher Scientific (Waltham, MA, USA). Magnesium sulfate (anhydrous powder) and acetic acid (glacial) were obtained from J.T. Baker. Triethylamine (99\%) was obtained from Lancaster Synthesis (Windham, NH, USA). Acetonitrile (GR ACS) was obtained from EMD Chemicals.

\subsubsection{4(5)-Vinylimidazole (1)}

The chemical 4(5)-Vinylimidazole was synthesized by decarboxylation of urocanic acid. The procedure employed was analogous to that of Overberger, et al. [43]. Thus, urocanic acid $(3.70 \mathrm{~g}, 26.8 \mathrm{mmol})$ was decarboxylated in vacuo $(10 \mu \mathrm{m} \mathrm{Hg})$ at $230{ }^{\circ} \mathrm{C}$ to yield $1.46 \mathrm{~g}(58 \%)$ of crude $4(5)$-vinylimidazole.

\subsubsection{1-Trityl-4-vinylimidazole (2)}

The chemical 1-Trityl-4-vinylimidazole was synthesized by a procedure analogous to that of Schiavone, et al [44]. Thus, $(10 \mathrm{~g}, 0.11 \mathrm{~mol})$ of crude $4(5)$-vinylimidazole was reacted with triphenylmethyl chloride $(32.6 \mathrm{~g}, 117 \mathrm{mmol})$ to provide a quantitative yield $(36 \mathrm{~g})$ of 1-trityl-4-vinylimidazole.

\subsubsection{1-Trityl-2-methyl-4-vinylimidazole (3)}

The chemical 1-Trityl-2-methyl-4-vinylimidazole was synthesized by a procedure analogous to that alluded to by Schiavone et al. [44], in which 1-trityl-4-vinylimidazole $(12 \mathrm{~g}, 36 \mathrm{mmol})$ in dry tetrahydrofuran $(600 \mathrm{~mL}$, distilled from sodium benzophenone ketyl) under argon was lithiated ( $25.5 \mathrm{~mL}, 36 \mathrm{mmol}, 1.4 \mathrm{M} \mathrm{sec}$-butyl lithium in cyclohexane). The reaction mixture, which turned deep red upon addition of sec-butyl lithium, was stirred in an ice water bath for $15 \mathrm{~min}$ and held for $2 \mathrm{~h}$ at room temperature prior to alkylation with iodomethane $(3 \mathrm{~mL}, 0.05 \mathrm{~mol})$. The resultant yellow solution was stirred at room temperature for $30 \mathrm{~min}$ and quenched with distilled water $(100 \mathrm{~mL})$. THF was removed by rotary evaporation and the aqueous residue was exhaustively extracted with chloroform. The chloroform extract was dried over magnesium sulfate and filtered, prior to removal of the solvent in vacuo, leaving a yellow solid, 1-trityl-2-methyl-4-vinylimidazole. Crude yield $=9.3 \mathrm{~g}, 74 \%$.

\subsubsection{2-Methyl-4-vinylimidazole (4)}

Crude 1-trityl-2-methyl-4-vinylimidazole $(5.7 \mathrm{~g}, 16.4 \mathrm{mmol})$ was charged to a $500 \mathrm{~mL}$ single-neck, round-bottom flask equipped with a reflux condenser. An amount of $5 \%$ acetic acid-methanol $(200 \mathrm{~mL})$ was added to the flask and the reaction mixture was refluxed for $40 \mathrm{~min}$, heating in a $75^{\circ} \mathrm{C}$ oil bath. The solvent was removed by rotary evaporation and $50 \mathrm{~mL}$ of distilled water was added. A white precipitate formed immediately. The precipitate was centrifuged down and the water layer was decanted to another $200 \mathrm{~mL}$ single-neck, round-bottom flask. Residual water was removed in vacuo to yield 2-methyl4 -vinylimidazole as a clear yellow oily residue: yield $=0.45 \mathrm{~g}, 25 \%$. The reaction was then increased in scale to prepare $25 \mathrm{~g}$ of crude 2-methyl-4-vinylimidazole that was purified by crystallization from ethyl acetate. Thus, $10.5 \mathrm{~g}$ of crude 2-methyl-4-vinylimidazole was charged to a $250 \mathrm{~mL}$ Erlenmeyer flask and warmed to dissolve in a minimum amount of ethyl acetate. The solution was cooled, held at room temperature for $1 \mathrm{~h}$, and subsequently stored in a refrigerator at $0{ }^{\circ} \mathrm{C}$ for 3 days. Needle-like white crystals formed and were collected by vacuum filtration: yield $=8.65 \mathrm{~g}, 82 \%-{ }^{1} \mathrm{H} \mathrm{nmR}$ (in methanol-d4) $2.38(3 \mathrm{H}, \mathrm{s}$, $\left.-\mathrm{CH}_{3}\right) ; 6.50(1 \mathrm{H}, \mathrm{m}$, vinyl H-C); $5.01(1 \mathrm{H}$, q, trans-vinyl H); $5.58(1 \mathrm{H}$, q, cis vinyl $\mathrm{H}) ; 6.97$ $(1 \mathrm{H}, \mathrm{s}, \mathrm{C}-5 \mathrm{H})$. 


\subsubsection{1-Butyl-2-methyl-4-vinylimidazole (5)}

Crystalline 2-methyl-4-vinylimidazole $(2.15 \mathrm{~g}, 19.7 \mathrm{mmol})$ and tetrahydrofuran $(20 \mathrm{~mL})$ were charged to a $150 \mathrm{~mL}$ round-bottomed flask, equipped with y-tube, rubber stopper, reflux condenser with gas inlet, and magnetic stirring bar. The suspension was stirred under argon and cooled in an ice bath. Potassium tert-butoxide, $1 \mathrm{M}$ in tetrahydrofuran $(39.5 \mathrm{~mL}, 39.5 \mathrm{mmol})$, was injected into the flask and the reaction mixture, which turned milky white and was left to stir for $15 \mathrm{~min}$. n-Butyl bromide $(2.55 \mathrm{~mL}, 23.7 \mathrm{mmol})$ was added drop-wise and the reaction mixture was held under Ar at ambient temperature and stirred overnight prior to the removal of the solvent in vacuo to yield a yellow oil that was dissolved in $50 \mathrm{~mL}$ of diethyl ether. The ether solution was washed with $100 \mathrm{~mL}$ of $5 \%$ aqueous hydrochloric acid and separated from the water layer. Potassium carbonate was added to the aqueous layer until the $\mathrm{pH}$ increased to 11 . The aqueous layer was then extracted three times with $100 \mathrm{~mL}$ aliquots of diethyl ether. All ether solutions were combined and dried over magnesium sulfate. The ethereal solution was filtered and the solvent was removed via rotary evaporation to give a light-yellow oil: yield $=0.8 \mathrm{~g}, 25 \%$.

Crude 1-butyl-2-methyl-4-vinylimidazole $(1.50 \mathrm{~g}, 9.15 \mathrm{mmol})$, synthesized as described above at a larger scale, was charged to a $10 \mathrm{~mL}$ one-necked round bottom flask, equipped with a vacuum-jacketed, short path distillation head. The crude monomer was distilled in vacuo to yield $0.84 \mathrm{~g}(56 \%)$ of "pure" 1-butyl-2-methyl-4-vinylimidazole. The clear colorless product was stored at $0{ }^{\circ} \mathrm{C}:{ }^{1} \mathrm{H} \mathrm{nmR}$ (in methanol-d4) $0.88(3 \mathrm{H}, \mathrm{t}$, $\left.\mathrm{N}-\left(\mathrm{CH}_{2}\right)_{3} \mathrm{CH}_{3}\right) ; 1.35\left(2 \mathrm{H}, \mathrm{m}, \mathrm{N}-\mathrm{CH}_{2} \mathrm{CH}_{2} \mathrm{CH}_{2} \mathrm{CH}_{3}\right) ; 1.62\left(2 \mathrm{H}, \mathrm{m}, \mathrm{N}-\mathrm{CH}_{2} \mathrm{CH}_{2} \mathrm{CH}_{2} \mathrm{CH}_{3}\right)$; $3.73\left(2 \mathrm{H}, \mathrm{t}, \mathrm{N}-\mathrm{CH}_{2} \mathrm{CH}_{2} \mathrm{CH}_{2} \mathrm{CH}_{3}\right) ; 2.32\left(3 \mathrm{H}, \mathrm{s},-\mathrm{C}-2 \mathrm{CH}_{3}\right) ; 5.01(1 \mathrm{H}, \mathrm{d} / \mathrm{d}$, trans-vinyl $\mathrm{H})$; $5.68(1 \mathrm{H}, \mathrm{d} / \mathrm{d}$, cis-vinyl $\mathrm{H}) ; 6.47(1 \mathrm{H}$, q, vinyl $\mathrm{H}-\mathrm{C}) ; 6.70(1 \mathrm{H}, \mathrm{s}, \mathrm{C}-5 \mathrm{H})$. The ${ }^{1} \mathrm{H} \mathrm{nmR}$ spectrum shows the presence of a very small amount (less than $5 \%$ ) of 1-butyl-2-methyl-5vinylimidazole.

\subsubsection{1-Butyl-2,3-dimethyl-4-vinylimidazolium Triflate (6)}

Freshly distilled 1-butyl-2-methyl-4-vinylimidazole $(0.84 \mathrm{~g}, 5.1 \mathrm{mmol})$, containing a small amount of 1-butyl-2-methyl-5-vinylimidazole and $8 \mathrm{~mL}$ dichloromethane, was charged to a $50 \mathrm{~mL}$ one-neck, round-bottom flask, equipped with y-tube, rubber serum cap, reflux condenser with gas inlet, and magnetic stir bar. The vessel was immersed in ice bath. Under an argon blanket, methyl trifluoromethanesulfonate $(0.69 \mathrm{~mL}, 6.1 \mathrm{mmol})$, which was dissolved in $10 \mathrm{~mL}$ of dichloromethane, was added drop-wise by syringe. The reaction mixture was stirred at $0{ }^{\circ} \mathrm{C}$ for $2 \mathrm{~h}$ prior to removal of dichloromethane and unreacted methyl trifluoromethanesulfonate, in vacuo, at $0^{\circ} \mathrm{C}$, to provide a white crystalline product melting at $45{ }^{\circ} \mathrm{C}$ : yield $=1.68 \mathrm{~g}, 100 \%-{ }^{1} \mathrm{H} \mathrm{nmR}$ (in methanol-d4) $0.92(3 \mathrm{H}, \mathrm{t}$, $\left.\mathrm{N}-\left(\mathrm{CH}_{2}\right)_{3} \mathrm{CH}_{3}\right) ; 1.35\left(2 \mathrm{H}, \mathrm{m}, \mathrm{N}-\mathrm{CH}_{2} \mathrm{CH}_{2} \mathrm{CH}_{2} \mathrm{CH}_{3}\right) ; 1.75\left(2 \mathrm{H}, \mathrm{m}, \mathrm{N}-\mathrm{CH}_{2} \mathrm{CH}_{2} \mathrm{CH}_{2} \mathrm{CH}_{3}\right)$; $4.09\left(2 \mathrm{H}, \mathrm{t}, \mathrm{N}-\mathrm{CH}_{2} \mathrm{CH}_{2} \mathrm{CH}_{2} \mathrm{CH}_{3}\right) ; 2.54\left(3 \mathrm{H}, \mathrm{s},-\mathrm{C}^{2}-\mathrm{CH}_{3}\right) ; 3.73\left(3 \mathrm{H}, \mathrm{s}, \mathrm{N}-\mathrm{CH}_{3}\right) ; 5.53(1 \mathrm{H}$, $\mathrm{d} / \mathrm{d}$, cis-vinyl $\mathrm{H}) ; 5.83(1 \mathrm{H}, \mathrm{d} / \mathrm{d}$, trans-vinyl H); $6.60(1 \mathrm{H}$, m, vinyl H-C); $7.66(1 \mathrm{H}, \mathrm{s}, \mathrm{C}-5 \mathrm{H})$.

\subsection{Polymerization of 1-Butyl-2,3-dimethyl-4-vinylimidazolium Triflate}

1-Butyl-2,3-dimethyl-4-vinylimidazolium trifluoromethanesulfonate $(1.68 \mathrm{~g}, 5.80 \mathrm{mmol})$ was dissolved in ethyl acetate $(8 \mathrm{~mL})$ and ethanol $(2 \mathrm{~mL})$ and charged to a polymerization tube at $0{ }^{\circ} \mathrm{C}$. A 0.012 molar solution of AIBN in ethyl acetate $(1 \mathrm{~mL})$ was added to the polymerization tube, and the reaction mixture was degassed in three freeze-thaw cycles, the flame sealed, and immersed in a water bath at $65{ }^{\circ} \mathrm{C}$ for $20 \mathrm{~h}$. A viscous polymer solution was formed. The polymerization tube was opened and the reaction mixture was precipitated in $300 \mathrm{~mL}$ of diethyl ether. The product was isolated by centrifugation and dried in an inert atmosphere to yield $1.68 \mathrm{~g}, 100 \%$, of a fluffy white polymer, $\mathrm{M}_{\mathrm{n}} \sim 39.6 \mathrm{kDa}$, polydispersity $=1.75$.

\subsection{Ion Exchange of Poly(1-Butyl-2,3-dimethyl-4-vinylimidazolium Triflate)}

A "stock solution" with a concentration of $0.02 \mathrm{~g} / \mathrm{mL}$ of poly(1-butyl-2,3-dimethyl4 -vinylimidazolium triflate) in methanol was used in the ion exchange process. Thus, 
$10 \mathrm{~mL}$ aliquots $(\sim 0.70 \mathrm{mmol})$ of stock solution was mixed with $10 \mathrm{~mL}$ aliquots $(\sim 0.90 \mathrm{mmol})$ of methanolic solutions of lithium trifluoromethylsulfonamide or ammonium hexafluorophosphate. The precipitate that formed immediately upon mixing the two solutions was isolated by centrifugation and washed repeatedly with methanol to yield poly(1butyl-2,3-dimethyl-4-vinylimidazolium trifluoromethylsulfonylimide) and poly(1-butyl2,3-dimethyl-4-vinylimidazolium hexafluorophosphate), respectively. In order to ensure that these polymers were fully ion-exchanged, the wet trifluoromethylsulfonylimide (TFSI) and hexafluorophosphate $\left(\mathrm{PF}_{6}{ }^{-}\right)$salts were washed with additional aliquots of methanolic solutions of lithium TFSI and ammonium $\mathrm{PF}_{6}{ }^{-}$. These wet precipitates were exhaustively washed with methanol to remove any excess $\mathrm{TFSI}^{-}$or $\mathrm{PF}_{6}{ }^{-}$salts. The efficiency of this process in affecting full ion exchange was validated by comparative ${ }^{19} \mathrm{~F} \mathrm{nmR}$ of the $\mathrm{PF}_{6}{ }^{-}$ polymer and the pure, not ion-exchanged, $\mathrm{CF}_{3} \mathrm{SO}_{3}{ }^{-}$polymer that showed no signal for the fluorine bound to a trifluoromethyl moiety in the ion-exchanged $\mathrm{PF}_{6}{ }^{-}$polymer.

The ion-exchanged polymers were dried in vacuo prior to thermal analysis.

\section{Results and Discussion}

\subsection{Synthesis and Ion Exchange of Poly(1-Butyl-2,3-dimethyl-4-vinylimidazolium Triflate)}

The vinylimidazolium polymers, which have a hydrogen atom on the 2-position on the imidazolium ring, may be candidates for membrane electrolytes in capacitive electrochemical devices. However, in battery applications, the acidic hydrogen at the 2-position of the imidazole ring may react with electrons formed at the cathode, releasing hydrogen gas and causing irreversibility in charging-discharging cycles [41]. A solution to this potential problem is the synthesis of 2-methylimidazolium polymers with structures such as those shown in Figure 2. The family of 1-butyl-2,3-dimethyl-4-vinylimidazolium polymers with triflate $\left(\mathrm{Tf}^{-}\right)$, hexafluorophosphate $\left(\mathrm{PF}_{6}{ }^{-}\right)$and trifluoromethylsulfonylimide $\left(\mathrm{TFSI}^{-}\right.$) anions was synthesized using procedures described in detail in the Materials and Methods Section. Thus, freshly distilled, 1-butyl-2-methyl-4-vinylimidazole (5) was quaternized with methyltriflate to yield 1-butyl-2,3-dimethyl-4-vinylimidazolium triflate (6). The entire reaction sequence, starting from 4(5)-vinylimidazole, (1) is outlined below in Figure 4.

Each of the reactions in the sequence is inherently high yield; however, the yields of tautomeric 2-methyl-4(5)-vinylimidazole (4) and 1-butyl-2-methyl-4-vinylimidazole (5) were adversely impacted by difficulties in isolating them from their reaction mixtures. The butylation of (4) was highly regiospecific, as evidenced by the fact that the ${ }^{1} \mathrm{H}-\mathrm{NMR}$ spectrum of (5) showed only a miniscule amount of 1-butyl-2-methyl-5-vinylimidazole. The quaternization with methyl triflate was very facile with (5) being quantitatively converted to (6). The successful synthesis of (6), 1-butyl-2,3-dimethyl-4-vinylimidazolium triflate, is confirmed by its ${ }^{1} \mathrm{H}-\mathrm{NMR}$ spectrum shown in Figure 5.

The chemical 1-Butyl-2,3-dimethyl-4-vinylimidazolium triflate was homopolymerized free-radically in ethyl acetate, initiating with AIBN, and was isolated and dried in accordance with the procedure detailed in the Materials and Methods Section. The poly(styrene) equivalent number average molecular weight was $~ 39.6 \mathrm{KDa}$; the polydispersity was 1.75 . The ${ }^{1} \mathrm{H}$ nmR spectrum of poly(1-butyl-2,3-dimethyl-4-vinylimidazolium triflate), P23DM4VIm ${ }^{+} \mathrm{Tf}^{-}$, is shown in Figure 6. The extraneous peak at about 2.9 ppm corresponds to residual protons in the DMSO- $\mathrm{d}_{6}$.

As described in the Materials and Methods section, a methanolic solution of P23DM4VIm ${ }^{+}$ $\mathrm{Tf}^{-}$was ion exchanged with methanolic solutions of trifluoromethylsulfonylimide, $\left(\mathrm{TFSI}^{-}\right.$) and hexafluorophosphate, $\left(\mathrm{PF}_{6}{ }^{-}\right)$salts, respectively. The resultant P23DM4VIm ${ }^{+} \mathrm{TFSI}^{-}$ and $\mathrm{P} 23 \mathrm{DM} 4 \mathrm{VIm}^{+} \mathrm{PF}_{6}{ }^{-}$salts precipitated from the mixed methanol solutions, and the precipitates were washed with methanolic solutions of $\mathrm{TFSI}^{-}$and $\mathrm{PF}_{6}{ }^{-}$salts to ensure full ion-exchange. 
(1)<smiles>C=Cc1cn([TlH])c[nH+]1</smiles>

(5)

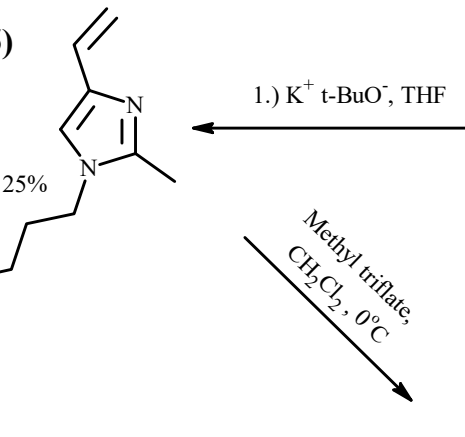

1.) N,N'-DMF, $\left(\mathrm{CH}_{3} \mathrm{CH}_{2}\right)_{3} \mathrm{~N}$

2.) dilute aqueous $\mathrm{HCl}$
(2)

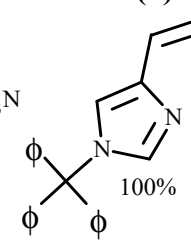

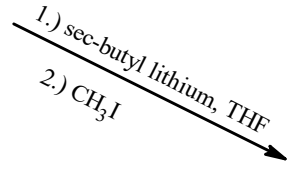

(4)

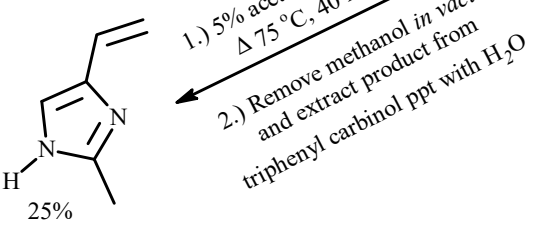

(6)

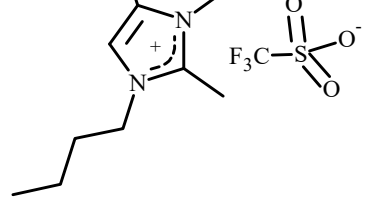

Figure 4. Synthesis of 1-butyl-2,3-dimethyl-4-vinylimidazolium triflate.

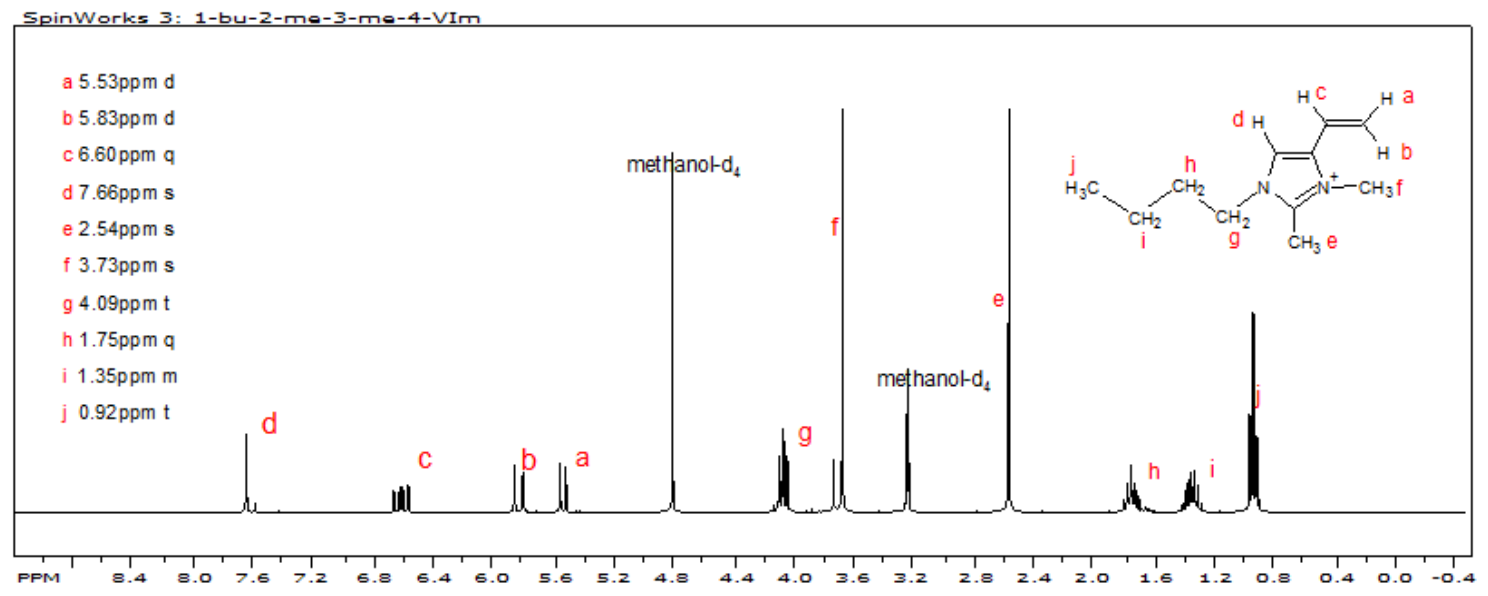

Figure 5. ${ }^{1} \mathrm{H}$ nmR spectrum of 1-butyl-2,3-dimethyl-4-vinylimidazolium triflate. 


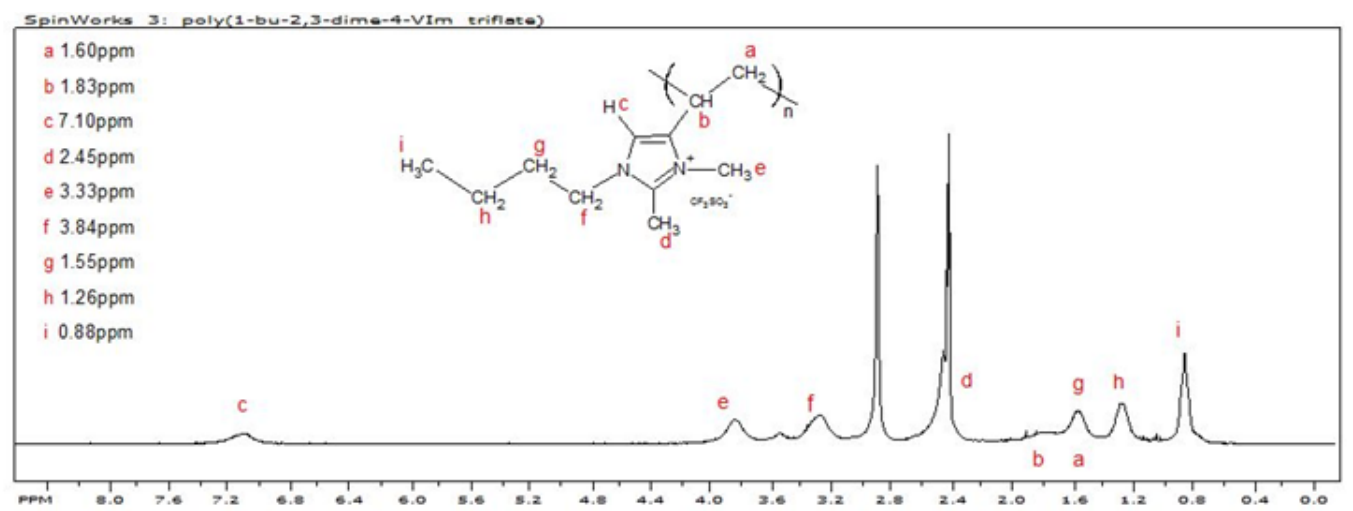

Figure 6. ${ }^{1} \mathrm{H}$ nmR spectrum of poly(1-butyl-2,3-dimethyl-4-vinylimidazolium triflate).

The efficiency of this process in affecting full ion exchange was validated by comparative ${ }^{19} \mathrm{~F}$ nmR of the $\mathrm{PF}_{6}{ }^{-}$polymer and the pure, not-ion-exchanged $\mathrm{CF}_{3} \mathrm{SO}_{3}{ }^{-}$polymer that showed no signal for the fluorine bound to a trifluoromethyl moiety in the ion-exchanged $\mathrm{PF}_{6}{ }^{-}$polymer.

\subsection{The Glass Transition in Ionic Polymers}

In their ground-breaking study of the glass transition in several families of ionic polymers, Eisenberg et al. [45] concluded that the $\mathrm{T}_{\mathrm{g}}$ of ionic polymers was determined by the magnitude of the cation-anion interaction and that $\mathrm{T}_{\mathrm{g}}$ was directly proportional to the ratio of the charge on the ion and the separation between the ionic moiety tethered to the polymer and its counterion, $q / a$. This conclusion was supported by studies of phosphate, silicate, acrylate and aliphatic ionene polymer systems. [45,46] Eisenberg et al. found that the slope of plots of $\mathrm{T}_{\mathrm{g}}$ versus $q / a$ in these three polymer systems ranged from 625 to 730 . Building on these works, Tsutsui and Tanaka [47] and Peiffer [48] found the glass transition temperature of ionic polymers to be dependent on the molar ionic cohesive energy, the universal gas constant, and a factor related to intramolecular interactions. They derived Equation (1), which fitted the $\mathrm{T}_{\mathrm{g}}$ versus $q / a$ data for phosphate, acrylate and aliphatic ionene polymer systems:

$$
\mathrm{T}_{\mathrm{g}}=\frac{2 N_{A} e^{2}}{3 C R}\left(\frac{q}{a}\right)+\frac{12}{R}(25)
$$

where $N_{A}$ is Avogadro's number, e is the electronic charge, $C$ is a constant, $q / a$ is the ratio of the charge on the ion to the separation between the ion pair, and $R$ is the universal gas constant. Given the glass transition data reported in the literature for 3-ethyl-1vinylimidazolium polymers [12,27,33] and 3-butyl-1-vinylimidazolium polymers, [12] the relationship between $T_{g}$ and $q / a$ can be evaluated for vinylimidazolium polymers. These data, along with their associated molecular ion volumes [49] and ionic radii, are shown in Table 1.

Table 1. $\mathrm{T}_{\mathrm{g}}$ of Poly(3-ethyl-1-vinylimidazolium) and Poly(3-butyl-1-vinylimidazolium) salts. [12].

\begin{tabular}{|c|c|c|c|c|c|c|c|c|}
\hline \multicolumn{9}{|c|}{ Anion (Volume, $\mathrm{nm}^{3}$ ) [46] } \\
\hline \multirow{2}{*}{ Polymer Composition } & \multicolumn{2}{|c|}{$\begin{array}{c}\mathrm{Br}^{-} \\
(0.054 \pm 0.007)\end{array}$} & \multicolumn{2}{|c|}{$\begin{array}{c}\mathrm{BF}_{4}^{-} \\
(0.073 \pm 0.009)\end{array}$} & \multicolumn{2}{|c|}{$\begin{array}{c}\mathrm{Tf}^{-} \\
(0.131 \pm \mathbf{0 . 0 1 5})\end{array}$} & \multicolumn{2}{|c|}{$\begin{array}{c}\text { TFSI }^{-} \\
(0.232 \pm 0.015)\end{array}$} \\
\hline & PEVIm $^{+}$ & PBVIm $^{+}$ & PEVIm $^{+}$ & PBVIm $^{+}$ & PEVIm $^{+}$ & PBVIm $^{+}$ & PEVIm $^{+}$ & PBVIm ${ }^{+}$ \\
\hline $\mathrm{T}_{\mathrm{g}}, \mathrm{K}$ & $\begin{array}{c}490 \\
508[27]\end{array}$ & 465 & 454 & 421 & $\begin{array}{c}418 \\
413 \text { [29] }\end{array}$ & 407 & $\begin{array}{c}329 \\
370[29] \\
333[27]\end{array}$ & 321 \\
\hline$a, \AA$ & 5.71 & 5.97 & 5.93 & 6.19 & 6.49 & 6.75 & 7.15 & 7.41 \\
\hline$q / a^{*}$ & 0.175 & 0.167 & 0.169 & 0.161 & 0.154 & 0.148 & 0.140 & 0.135 \\
\hline
\end{tabular}


When plotting the data from Table $1, \mathrm{~T}(\mathrm{~K})$ versus the ratio of $\mathrm{q}$ (in units of 1 electron) over $a$ (in Angströms), one sees (Figure 7) a linear dependence of $\mathrm{T}_{\mathrm{g}}$ on $q / a$ with a slope of 608. Thus, the glass transition temperatures of poly(ionic liquids) derived from 1vinylimidazolium polymers appear to be linearly related to the ratio of the charge on the ion and the separation between the ionic moiety tethered to the polymer and its counterion, $q / a$. Moreover, the slope of the plot is close to those reported in the historic literature by Eisenberg, et al. for phosphate, silicate, acrylate and aliphatic ionene polymer systems $[45,46]$.

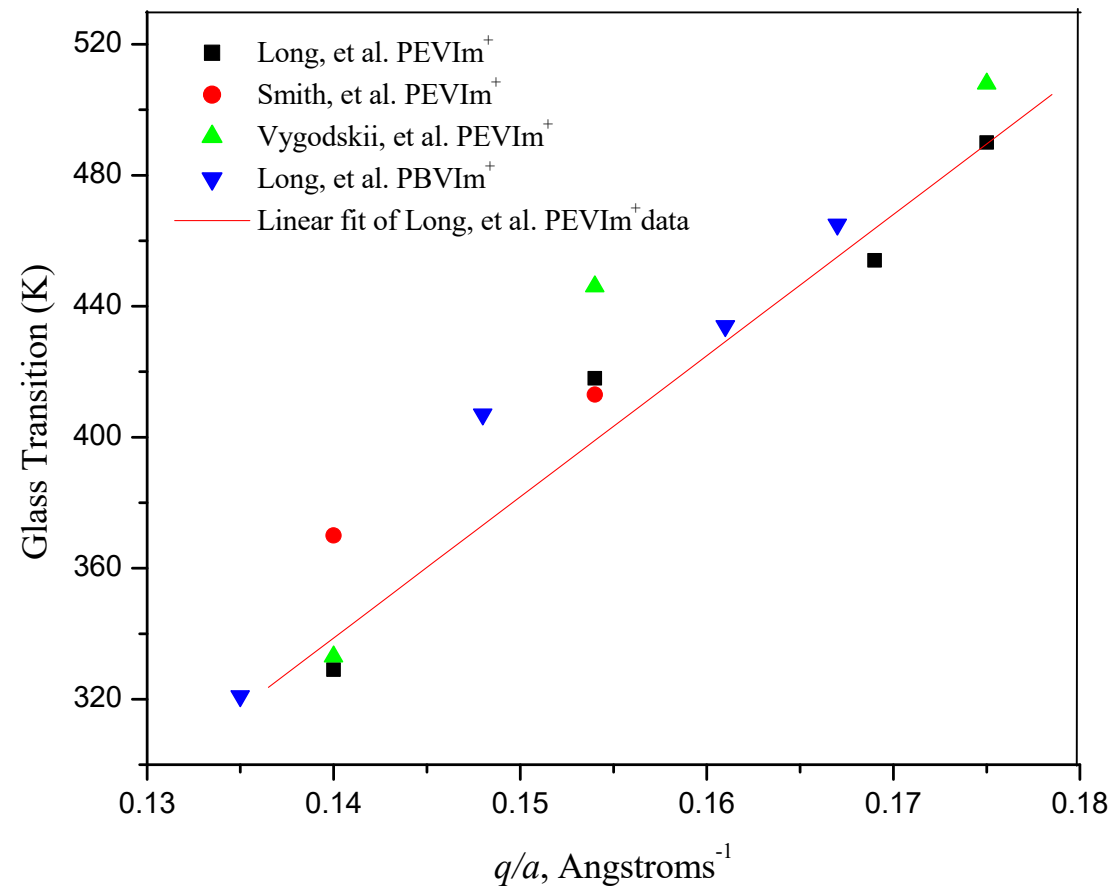

Figure 7. Glass transition temperature $(K)$ versus the ratio of the charge on the ion and the separation between the ion pair, $q / a$, for poly(3-ethy-1-vinylimidazolium) and poly(3-butyl-1-vinylimidazolium) salts. ( $\boldsymbol{\square}$ and $\boldsymbol{\Delta}$ Long et al. [12]; • Smith et al. [33]; $\Delta$ Vygodskii et al. [27]).

The molecular volume of $\mathrm{PEVIm}^{+}$is taken to be $0.156 \pm 0.018 \mathrm{~nm}^{3}$, equal to that reported for EMIm ${ }^{+}$[49]. The molecular volume of $\mathrm{PBVIm}^{+}$is taken to be $0.196 \pm 0.0 .021 \mathrm{~nm}^{3}$, equal to that reported for C4MIm ${ }^{+}$[49]. Assuming anions and cations to be spherical, ionic radii of the respective ions and respective anions and cation were calculated from the molecular volume of ions [50]. The distance between the anion and the cation, $a$, was calculated as the sum of the radii of the respective anions and cations.

\subsection{The Glass Transition in P23DM4VIm ${ }^{+}$Salts}

In the present work, the glass transition characteristics of $\mathrm{P} 23 \mathrm{DM} 4 \mathrm{VIm}^{+} \mathrm{Tf}^{-}, \mathrm{PF}_{6}{ }^{-}$, and TFSI $^{-}$salts were evaluated by differential scanning calorimetry. The thermograms for these salts are similar to each other (see Supplementary Materials) with the heat capacity change around the glass transition temperature for all salts in this group of 2-methylimidazolium polymers exhibiting an "excess enthalpy" peak, often seen as a result of densification, in aged polymer glasses [51]. Enthalpic relaxation peaks are also often seen when materials are rapidly cooled to a temperature far below their $\mathrm{T}_{\mathrm{g}}$ [52]. In the heating cycle, the $\mathrm{T}_{\mathrm{g}}$ mid of the triflate salt is $371 \mathrm{~K}\left(98^{\circ} \mathrm{C}\right)$. $\mathrm{T}_{\mathrm{g}}$-mid of the trifluoromethylsulfonylimide salt is $372 \mathrm{~K}\left(99^{\circ} \mathrm{C}\right)$, nearly identical to that of the triflate salt. The heating cycle glass transition temperature for the hexafluorophosphate salt is $357 \mathrm{~K}\left(84^{\circ} \mathrm{C}\right)$. The glass transition temperatures of all three polymers are, therefore, very close to each other. In light of the strong dependence of the $\mathrm{T}_{\mathrm{g}}$ of 1-vinylimidazolium polymers $\left(\mathrm{PEVIm}^{+}\right.$and $\left.\mathrm{PBVIm}^{+}\right)$on the distance separating the ion pair, evidenced in Figure 7, and the substantial differences 
in the glass transition temperatures of the corresponding P4VIm ${ }^{+}$salts [33], the proximity in the glass transition temperatures of the P23DM4VIm ${ }^{+}$salts is surprising. The mid-point glass transition temperatures of P23DM4VIm ${ }^{+}$salts derived from 1-butyl-2,3-dimethyl-4vinylimidazolium polymers, and those of the corresponding $\mathrm{P} \mathrm{VIm}^{+}$salts derived from 1-ethyl-3-methyl-4-vinylimidazolium polymers, are displayed in Table 2. Pertinent information on the molecular volume of anions and imidazolium cations and the distance separating the ion pairs is also included in Table 2.

Table 2. Poly(1-butyl-2,3-dimethyl-4-vinylimidazolium) and poly(1-ethyl-3-methyl-4-vinylimidazolium) salts.

\begin{tabular}{|c|c|c|c|c|c|c|}
\hline \multirow{2}{*}{$\begin{array}{c}\text { Polymer } \\
\text { Composition }\end{array}$} & \multicolumn{2}{|c|}{$\begin{array}{c}\mathrm{Tf}^{-} \\
(0.131 \pm \mathbf{0 . 0 1 5})\end{array}$} & \multicolumn{2}{|c|}{$\begin{array}{c}\text { TFSI }^{-} \\
(0.232 \pm 0.015)\end{array}$} & \multicolumn{2}{|c|}{$\begin{array}{c}\mathrm{PF}_{6}^{-} \\
(0.109 \pm 0.008)\end{array}$} \\
\hline & P23D4VIm $^{+}$ & P4VIm ${ }^{+}$ & P23D4VIm ${ }^{+}$ & P4VIm ${ }^{+}$ & P23D4VIm ${ }^{+}$ & P4VIm ${ }^{+}$ \\
\hline $\mathrm{T}_{\mathrm{g}}, \mathrm{K}$ & 371 & 426 [29] & 372 & 361 [29] & 357 & 473 [29] \\
\hline$a, \AA$ & 6.95 & 6.40 & 7.60 & 7.15 & 6.77 & 6.32 \\
\hline$q / a^{*}$ & 0.148 & 0.154 & 0.132 & 0.140 & 0.148 & 0.158 \\
\hline
\end{tabular}

* The quantity, $q / a$, is the ratio of the charge on the ion and the separation between the ionic moiety tethered to the polymer and its counterion.

Using the data in Table 2, the glass transition temperatures of $\mathrm{PF}_{6}{ }^{-}, \mathrm{Tf}^{-}$, and $\mathrm{TFSI}^{-}$salts of P23DM4VIm ${ }^{+}$and P4VIm ${ }^{+}$polymer salts are plotted below (see Figure 8 ) as a function of the ratio of the charge and the separation between the ionic moieties on the polymer.

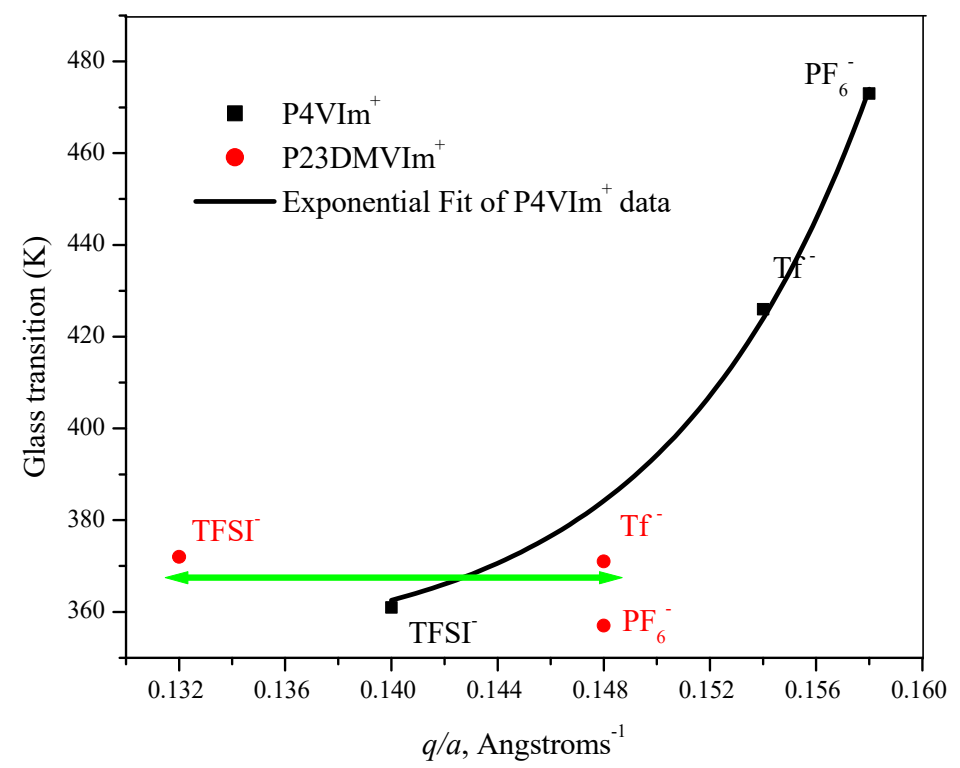

Figure 8. Glass transition temperature $(\mathrm{K})$ versus the ratio of the charge on the ion and the separation between the ion pair, $q / a$, for poly(1-ethyl-3-methyl-4-vinylimidazolium) and poly1-butyl-2,3dimethyl-4-vinylimidazolium) salts.

The molecular volume of 23DM4VIm ${ }^{+}$is assumed to be $0.229 \pm 0.012 \mathrm{~nm}^{3}$, equal to that reported for C4MMIm ${ }^{+}$[49]. The molecular volume of $4 \mathrm{VIm}^{+}$is assumed to be $0.156 \pm 0.018 \mathrm{~nm}^{3}$, equal to that reported for EMIm ${ }^{+}$[49]. Assuming anions and cations to be spherical, the ionic radii of the respective ions and respective anions and cation were calculated from the molecular volume of ions [50]. The distance between the anion and the cation, a, was calculated as the sum of the radii of the respective anions and cations.

As was observed with PEVIm ${ }^{+}$and PBVIm ${ }^{+}$salts, the P4VIm${ }^{+}$salts (see Figure 8) also show a strong dependence of the glass transition temperature on anion size and $\mathrm{q} / \mathrm{a}$. The line in the plot of the data in Table 2 for poly(1-ethy-3-methyl-4-vinylimidazolium) salts is the fit to a second-order exponential. It was demonstrated in our earlier work [33] that the $\mathrm{T}_{\mathrm{g}}$ of $\mathrm{P} 4 \mathrm{VIm}^{+} \mathrm{PF}_{6}{ }^{-}$is elevated by intramolecular bridging between imidazolium residues 
positioned 1,3- or 1,5- along the P4VIm ${ }^{+}$chain. Accordingly, the non-linearity of the plot for P4VIm ${ }^{+}$salts (Figure 8) as compared to that for PEVIm ${ }^{+}$and $\mathrm{PBVIm}^{+}$salts (Figure 7) is not unexpected.

In stark contrast to poly(vinylimidazolium salts) with a hydrogen at the 2-position of the imidazolium ring, the glass transition temperatures of $\mathrm{Tf}^{-}, \mathrm{TFSI}^{-}$and $\mathrm{PF}_{6}{ }^{-}$salts from

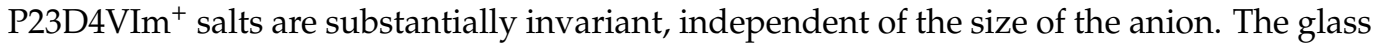
transition temperature of polymers in this set falls within a mere 15-degree temperature range, 357-372 K.

Figure 9 shows space-filling molecular renderings of 1-butyl-2,3-dimethyl-4vinylimidazolium triflate (Figure 9B) and 1-ethyl-3-methyl-4-vinylimidazolium triflate polymer triads (Figure 9A) that were created using the 3-D rendering tool in ACD ChemSketch (ACD, Toronto, ON, Canada).

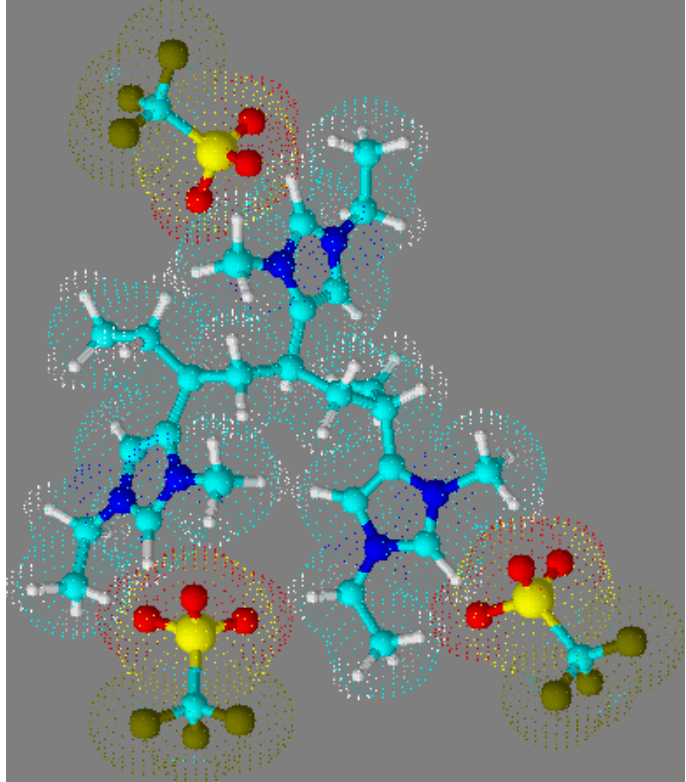

(A)

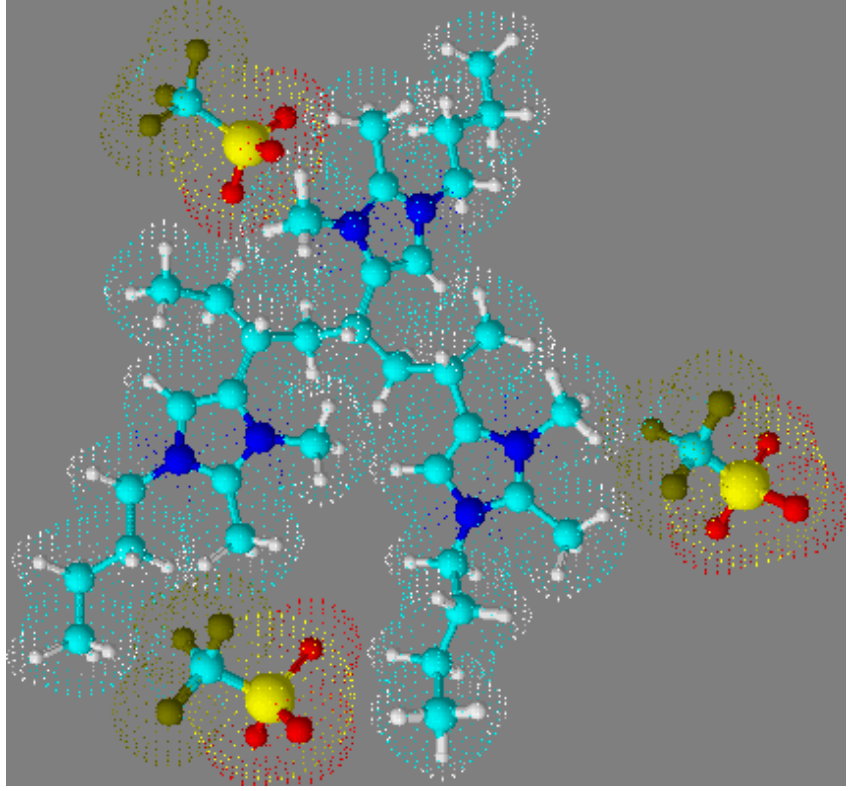

(B)

Figure 9. Space-filling molecular renderings of (A) 1-ethyl-3-methyl-4-vinylimidazolium triflate and (B) 1-butyl-2,3-dimethyl-4-vinylimidazolium triflate polymer triads.

These molecular renderings serve to illustrate that the proximity of the triflate anion to the imidazolium group is more hindered in the triad of P23D4VIm ${ }^{+}$(Figure 9B), wherein the 2-methyl substituent forces the triflate anion to be further removed from imidazolium moiety. On the basis of data in Table 2, one would estimate that the minimum distance separating the P23DM4VIm ${ }^{+}$cation and the triflate anion is $6.95 \AA$, while that separating the P4VIm ${ }^{+}$cation and the triflate anion is decreased to $6.77 \AA$. Given the substantive difference in the glass transition temperature of the triflate salts of P4VIm ${ }^{+}$and P23DM4VIm ${ }^{+}$, the methyl group at the 2-position of the imidazolium ring must be having a greater influence than simply forcing a $26 \%$ increase in the steric separation between the cation and anion. Fernandes et al. [53] carried out a systematic study on the relative interaction energies of ionic liquids. These authors report that while cation-anion interactions in ionic liquids are dominated by coulombic forces (the distance separating the ion pair), hydrogen bonding also plays an important role. For imidazolium-based ionic liquids the contribution of hydrogen bonding between the cation and the anion is determined by the acidic hydrogen in the 2-position of the imidazolium ring. In a work by Kirchner [54], this was quantified by comparing the interaction energies of 1-butyl-3-methylimidazolium trifluoromethylsulfonylimide $\left(\mathrm{BMIm}^{+} \mathrm{TFSI}^{-}\right.$) and 1-butyl-2,3-dimethylimidazolium trifluoromethylsulfonylimide $\left(\mathrm{DMIm}^{+} \mathrm{TFSI}^{-}\right)$, wherein an energetic difference between the two 
salts of $20 \mathrm{kJmol}^{-1}$ was calculated. The higher dissociation energy for the separation of the cation in $\mathrm{BMIm}^{+} \mathrm{TFSI}^{-}$as compared to $\mathrm{DMIm}^{+} \mathrm{TFSI}^{-}$was also observed experimentally in the work of Fernandes et al. [53], with values of relative interaction energies of 0.491 and $0.426 \mathrm{eV}$, respectively, being reported. It is thus reasonable to attribute the invariance in the glass transition of P23D4VIm ${ }^{+}$with different anions to a combination of minimal $\mathrm{H}$-bonding interactions between the respective anions and the $23 \mathrm{D} 4 \mathrm{VIm}^{+}$moiety and steric separation enforced by having substituents on the 1,2, 3, and 4 positions of the imidazolium ring.

\section{Summary and Conclusions}

The chemical 1-Butyl-2,3-dimethyl-4-vinylimidazolium triflate (2,3DM4VIm $\left.{ }^{+} \mathrm{Tf}^{-}\right)$was synthesized in a pure, dry (water-free) state by direct alkylation of 1-butyl-2-methyl-4vinylimidazole in $\mathrm{CH}_{2} \mathrm{Cl}_{2}$ with methyl triflate at $0^{\circ} \mathrm{C}$. Moreover, 2,3DM4 $\mathrm{VIm}^{+} \mathrm{Tf}^{-}$was polymerized with a free-radical initiator, and the resulting polymer was ion exchanged to create $\mathrm{PF}_{6}{ }^{-}$, and $\mathrm{TFSI}^{-}$salts. This may be the first literature report of the synthesis and polymerization of an ionic liquid vinylimidazolium monomer with a substituent at the 2-position of the imidazolium ring. The glass transition characteristics of $\mathrm{TFSI}^{-}, \mathrm{PF}_{6}{ }^{-}$and triflate salts of the tetrasubstituted $2,3 \mathrm{DM} 4 \mathrm{VIm}^{+}$polymers are anomalous as compared to those of corresponding TFSI ${ }^{-}, \mathrm{PF}_{6}{ }^{-}$and triflate salts of trisubstituted 4-vinylimidazolium polymers without a methyl substituent at the 2-position. The glass transition temperatures for the $\mathrm{P} 4 \mathrm{VIm}^{+}$salts vary from $88{ }^{\circ} \mathrm{C}$ for the $\mathrm{TFSI}^{-}$salt to $153{ }^{\circ} \mathrm{C}$ for the $\mathrm{CF}_{3} \mathrm{SO}_{3}{ }^{-}$salt and $200{ }^{\circ} \mathrm{C}$ for the $\mathrm{PF}_{6}{ }^{-}$salt. Those for the corresponding P23DM4VIm ${ }^{+}$salts are $99^{\circ} \mathrm{C}, 98^{\circ} \mathrm{C}$ and $84^{\circ} \mathrm{C}$, respectively.

The invariance in the glass transition of P23DM4VIm ${ }^{+}$with different anions is attributed to a combination of the steric separation enforced by having substituents on the $1-, 2-, 3-$, and 4- positions of the imidazolium moiety. This dramatically diminishes the contribution of the counterion size to the equilibrium distance between the center of the anion and cation and minimal H-bonding interactions in the 2-substituted imidazolium polymer salts. It is believed that this is the first observation of the substantial independence of the glass transition of an ionic polymer on the nature of its counterion. One might even speculate that the interaction between the ion pairs may be reduced to the point that the onset of motion of the polymer backbone is effectively decoupled from counterion motion.

Supplementary Materials: The following are available online at https: / www.mdpi.com/article / 10.3390/polym14020254/s1, Figure S1: TGA of poly(imidazolium) salts. Figure S2: DSC scans of P23DMVIm ${ }^{+} \mathrm{Tf}^{-}$. Figure S3: DSC scans of P23DMVIm ${ }^{+} \mathrm{TFSI}^{-}$. Figure S4: DSC scans of P23DMVIm ${ }^{+} \mathrm{PF}_{6}{ }^{-}$. Figure S5: ${ }^{1} \mathrm{H} \mathrm{nmR}$ of 2-methyl-4-vinylimidazole. Figure $\mathrm{S6}:{ }^{1} \mathrm{H} \mathrm{nmR}$ of 1 butyl-2-methyl-4-vinylimidazole. Figure S7: ${ }^{1} \mathrm{H}$ nmR of 1-butyl-2,3-dimethyl-4-vinylimidazolium triflate. Figure S8: ${ }^{1} \mathrm{H}$ nmR of poly(1-butyl-2,3-dimethyl-4-vinylimidazolium) triflate. Figure S9: ${ }^{19} \mathrm{~F}$ nmR of poly(1-butyl-2,3-dimethyl-4-vinylimidazolium triflate). Figure S10: ${ }^{19} \mathrm{~F} \mathrm{nmR}$ of poly(1butyl-2,3-dimethyl-4-vinylimidazolium hexafluorophosphate).

Author Contributions: Conceptualization, methodology and formal analysis T.W.S., F.Y., M.Z., D.S. and P.C.; investigation, F.Y., M.Z., S.L., T.A. and D.S.; writing-original draft preparation, T.W.S. and F.Y.; writing-review and editing, T.W.S.; supervision, project administration and funding acquisition T.W.S. and P.C. All authors have read and agreed to the published version of the manuscript.

Funding: This research was funded, in part, by the National Science Foundation, Polymers Program of the Division of Materials Research through DMR-0938957 and DMR-1206010.

Institutional Review Board Statement: Not applicable.

Informed Consent Statement: Not applicable. 


\begin{abstract}
Data Availability Statement: Data supporting reported results can be found through https:// scholarworks.rit.edu (accessed on 1 December 2021), in Darren Smith "Synthesis and characterization of poly(ionic liquids) derived from 1-ethyl-3-methyl-4-vinylimidazolium triflate" (2011); Fan Yang "Synthesis and Characterization of Ionic Liquid Monomers and Polymers Derived from 2substituted-1,3-dialkyl-4(5)-vinylimidazolium salts" (2012); and the RIT Ph.D. Dissertation of Meng Zhao "Thermal Analysis and Dielectric Spectral Characteristics of Poly(ionic Liquids): Towards exploration of their utility in capacitive electrochemical devices" (2014).
\end{abstract}

Conflicts of Interest: The authors declare no conflict of interest.

\title{
References
}

1. Fernicola, A.; Scrosati, B.; Ohno, H. Potentialities of ionic liquids as new electrolyte media in advanced electrochemical devices. Ionics 2006, 12, 95-102. [CrossRef]

2. Mecerreyes, D. Polymeric ionic liquids: Broadening the properties and applications of polyelectrolytes. Prog. Polym. Sci. 2011, 36, 1629. [CrossRef]

3. Hayashi, K.; Yasue Nemoto, Y.; Akuto, K.; Sakurai, Y. Ionic liquids for lithium Secondary Batteries. NTT Tech. Rev. 2004, 2, 48-54.

4. Appetecchi, G.B.; Kim, G.-T.; Montanino, M.; Carewska, M.; Marcilla, R.; Mecerreyes, D.; De Meatza, I. Ternary polymer electrolytes containing pyrrolidinium-based polymeric ionic liquids for lithium batteries. J. Power Source 2010, $195,3668$. [CrossRef]

5. Martinelli, A.; Matic, A.; Jacobsson, P.; Borjesson, L.; Fernicola, A.; Panero, S.; Scrosati, B.; Ohno, H. Physical properties of proton conducting membranes based on a protic ionic liquid. J. Phys. Chem. B 2007, 111, 12462-12467. [CrossRef] [PubMed]

6. Wu, B.; Hu, D.; Kuang, Y.; Liu, B.; Zhang, X.; Chen, J. Functionalization of carbon nanotubes by an ionic-liquid polymer: Dispersion of $\mathrm{Pt}$ and $\mathrm{PtRu}$ nanoparticles on carbon nanotubes and their electrocatalytic oxidation of methanol. Angew. Chem. Int. Ed. 2009, 48, 4751. [CrossRef] [PubMed]

7. Stenger-Smith, J.D.; Webber, C.K.; Anderson, N.; Chafin, A.P.; Zong, K.; Reynolds, J. Poly(3,4-alkylenedioxythiophene)-based supercapacitors using ionic liquids as supporting electrolytes. J. Electrochem. Soc. 2002, 149, A973-A977. [CrossRef]

8. Liew, C.-W.; Ramesh, S. Comparing Triflate and Hexafluorophosphate Anions of Ionic Liquids in Polymer Electrolytes for Supercapacitor Applications. Materials 2014, 7, 4019-4033. [CrossRef] [PubMed]

9. Wang, P.; Zakeeruddin, S.M.; Humphry-Baker, R.; Grätzel, M. A binary ionic liquid electrolyte to achieve $\geq 7 \%$ power conversion efficiencies in dye-sensitized solar cells. Chem. Mater. 2004, 16, 2694-2696. [CrossRef]

10. Zhao, J.; Shen, X.; Yan, F.; Qiu, L.; Leec, S.; Sun, B. Solvent-free ionic liquid/poly(ionic liquid) electrolytes for quasi-solid-state dye-sensitized solar cells. J. Mater. Chem. 2011, 21, 7326. [CrossRef]

11. Liu, S.; Liu, W.; Liu, Y.; Lin, J.-H.; Zhou, X.; Janik, M.J.; Colby, R.H.; Zhang, Q. Influence of imidazolium-based ionic liquids on the performance of ionic polymer conductor network composite actuators. Polym. Int. 2010, 59, 321-328. [CrossRef]

12. Green, M.D.; Salas-de la Cruz, D.; Ye, Y.; John, M.; Layman, J.M.; Elabd, Y.A.; Winey, K.I.; Long, T.E. Alkyl-Substituted NVinylimidazolium Polymerized Ionic Liquids: Thermal Properties and Ionic Conductivities. Macromol. Chem. Phys. 2011, 212, 2522-2528. [CrossRef]

13. Hunley, M.T.; England, J.P.; Long, T.E. Influence of Counteranion on the Thermal and Solution Behavior of Poly(2(dimethylamino)ethyl methacrylate)-Based Polyelectrolytes. Macromolecules 2010, 43, 9998. [CrossRef]

14. Chen, H.; Choi, J.-H.; Salas-de la Cruz, D.; Winey, K.I.; Elabd, Y.A. Polymerized Ionic Liquids: The Effect of Random Copolymer Composition on Ion Conduction. Macromolecules 2009, 42, 4809. [CrossRef]

15. Ye, Y.; Elabd, Y.A. Anion exchanged polymerized ionic liquids: High free volume single ion conductors. Polymer 2011, 52, 1309. [CrossRef]

16. Wang, S.-W.; Liu, W.; Colby, R.H. Counterion Dynamics in Polyurethane-Carboxylate Ionomers with Ionic Liquid Counterions. Chem. Mater. 2011, 23, 1862. [CrossRef]

17. Hirao, M.; Ito-Akita, K.; Ohno, H. Polymerization of molten salt monomers having a phenylimidazolium group. Polym. Adv. Technol. 2000, 11, 534. [CrossRef]

18. Matsumi, N.; Sugai, K.; Miyake, M.; Ohno, H. Polymerized Ionic Liquids via Hydroboration Polymerization as Single Ion Conductive Polymer Electrolytes. Macromolecules 2006, 39, 6924. [CrossRef]

19. Ogihara, W.; Washiro, S.; Nakajima, H.; Ohno, H. Effect of cation structure on the electrochemical and thermal properties of ion conductive polymers obtained from polymerizable ionic liquids. Electrochim. Acta 2006, 51, 2614. [CrossRef]

20. Ohno, H.; Yoshizawa, M.; Ogihara, W. Development of new class of ion conductive polymers based on ionic liquids. Electrochim. Acta 2004, 50, 255. [CrossRef]

21. Marcilla, R.; Blazquez, J.A.; Rodriguez, J.; Pomposo, J.A.; Mecerreyes, D. Tuning the solubility of polymerized ionic liquids by simple anion-exchange reactions. J. Polym. Sci. Part A Polym. Chem. 2004, 42, 208. [CrossRef]

22. Luo, S.-C.; Sun, S.; Deorukhkar, A.R.; Lu, J.-T.; Bhattacharyya, A.; Lin, J.B. Ionic liquids and ionic liquid crystals of vinyl functionalized imidazolium salts. J. Mater. Chem. 2011, 21, 1866. [CrossRef]

23. Yoshizawa, M.; Ogihara, W.; Ohno, H. Novel polymer electrolytes prepared by copolymerization of ionic liquid monomers. Polym. Adv. Technol. 2002, 13, 589. [CrossRef] 
24. Nakamura, K.; Saiwaki, T.; Fukao, K. Dielectric Relaxation Behavior of Polymerized Ionic Liquid. Macromolecules 2010, $43,6092$. [CrossRef]

25. Amajjahe, S.; Ritter, H. Anion Complexation of Vinylimidazolium Salts and Its Influence on Polymerization. Macromolecules 2008, 41, 716. [CrossRef]

26. Mori, H.; Yahagi, M.; Endo, T. RAFT Polymerization of N-Vinylimidazolium Salts and Synthesis of Thermoresponsive Ionic Liquid Block Copolymers. Macromolecules 2009, 42, 8082. [CrossRef]

27. Vygodskii, Y.S.; Melnik, O.A.; Shaplov, A.S.; Lozinskaya, E.I.; Malyshkina, I.A.; Gavrilova, N.D. Synthesis and ionic conductivity of polymer ionic liquids. Polym Sci. Ser. A 2007, 49, 256-261. [CrossRef]

28. Choi, U.H.; Mittal, A.; Price, T.L.; Gibson, H.W.; Runt, J.; Colby, R.H. Polymerized Ionic Liquids with Enhanced Static Dielectric Constants. Macromolecules 2013, 46, 1175-1186. [CrossRef]

29. Bocharova, V.; Wojnarowska, Z.; Cao, P.-F.; Fu, Y.; Kumar, R.; Li, B.; Novikov, V.N.; Zhao, S.; Kisliuk, A.; Saito, T.; et al. Influence of Chain Rigidity and Dielectric Constant on the Glass Transition Temperature in Polymerized Ionic Liquids. Phys. Chem. B 2017, 121, 11511-11519. [CrossRef]

30. Wang, Y.; Fan, F.; Agapov, A.L.; Yu, X.; Hong, K.; Mays, J.; Sokolov, A.P. Examination of the Fundamental Relation Between Ionic Transport and Segmental Relaxation in Polymer Electrolytes. Polymer 2014, 55, 4067-4076. [CrossRef]

31. Agapov, A.L.; Sokolov, A.P. Decoupling Ionic Conductivity from Structural Relaxation: A Way to Solid Polymer Electrolytes? Macromolecules 2011, 44, 4410-4414. [CrossRef]

32. Sasabe, H.; Saito, S. Relationship between Ionic Mobility and Segmental Mobility in Polymers in the liquid state. Polym. J. 1972, 3, 624-630. [CrossRef]

33. Smith, T.W.; Zhao, M.; Yang, F.; Smith, D.; Cebe, P. Imidazole Polymers Derived from Ionic Liquid 4-Vinylimidazolium Monomers: Their Synthesis and Thermal and Dielectric Properties. Macromolecules 2013, 46, 1133-1143. [CrossRef]

34. Ohno, H.; Ito, K. Room-temperature molten salt polymers as a matrix for fast ion conduction. Chem Lett. 1998, 6, 751-752. [CrossRef]

35. Hirao, M.; Ito, K.; Ohno, H. Preparation and polymerization of new organic molten salts; N-alkylimidazolium salt derivatives Electrochim. Acta 2000, 45, 1291-1294. [CrossRef]

36. Hsieh, Y.-N.; Horng, R.S.; Ho, W.-Y.; Huang, P.-C.; Hsu, C.-Y.; Whang, T.-J.; Kuei, C.-H. Characterizations for Vinylimidazolium Based Ionic Liquid Polymer Stationary Phases for Capillary Gas Chromatography. Chromatographia 2008, 67, 413. [CrossRef]

37. Green, M.D.; Long, T.E. Designing Imidazole-Based Ionic Liquids and Ionic Liquid Monomers for Emerging Technologies. J. Macromol. Sci. Part C Polym. Rev. 2009, 49, 291-314. [CrossRef]

38. Alder, R.W.; Allen, P.R.; Williams, S.J. Stable carbenes as strong bases. J. Chem. Soc. Chem. Commun. 1995, 1267-1268. [CrossRef]

39. Amyes, T.L.; Diver, S.T.; Richard, J.P.; Rivas, F.M.; Toth, K. Formation and stability of N-heterocyclic carbenes in water: The carbon acid pKa of imidazolium cations in aqueous solution. J. Am. Chem. Soc. 2004, 126, 4366-4374. [CrossRef] [PubMed]

40. Handy, S.T.; Okello, M. The 2-Position of Imidazolium Ionic Liquids: Substitution and Exchange. J. Org. Chem. 2005, 70, 1915-1918. [CrossRef] [PubMed]

41. Seki, S.; Kobayashi, Y.; Miyashiro, H.; Ohno, Y.; Usami, A.; Mita, Y.; Kihira, N.; Watanabe, M.; Terada, N. Lithium Secondary Batteries Using Modified-Imidazolium Room-Temperature Ionic Liquid. J. Phys. Chem. B 2006, 110, 10228-10230. [CrossRef]

42. Thomas, L.C. Use of multiple heating rate DSC and modulated temperature DSC to detect and analyze temperature-timedependent transitions in materials. Am. Lab. 2001, 33, 26-29. Available online: http://www.tainstruments.com/pdf/literature/ TA291.pdf (accessed on 20 April 2017).

43. Overberger, C.G.; Glowaky, R.C.; Pacansky, T.J.; Sannes, K.N. Poly [4(5)-vinylimidazole]. Macromol. Synth. 1974, 5, 43-49.

44. Schiavone, R.J.; Overberger, C.G. Reactions and Polymerization of 1-Trityl-4-Vinylimidazole. J. Polym. Chem. Part A Polym. Chem. 1988, 26, 107-115. [CrossRef]

45. Eisenberg, A. Glass transitions in ionic polymers. Macromolecules 1971, 4, 125-129. [CrossRef]

46. Eisenberg, A.; Matsuura, H.; Yokoyama, T. The Glass Transition of Aliphatic Ionenes. Polym. J. 1971, 2, 117-123. [CrossRef]

47. Tsutsui, T.; Tanaka, T. Role of electrostatic forces in the glass transition temperatures of ionic polymers. Polymer 1977, $18,817$. [CrossRef]

48. Peiffer, D.G. Intramolecular mobility and its role in the glass transition temperature of ionic polymers. Polymer 1980, 21, 1135-1138. [CrossRef]

49. Krossing, I.; Slattery, J.M.; Daguenet, C.; Dyson, P.J.; Oleinikova, A.; Weingärtner, H. Why Are Ionic Liquids Liquid? A Simple Explanation Based on Lattice and Solvation Energies. J. Am. Chem. Soc. 2006, 128, 13427-13434. [CrossRef]

50. Slattery, J.M.; Daguenet, C.; Dyson, P.J.; Schubert, T.J.; Krossing, I. How to predict the physical properties of ionic liquids: A volume-based approach. Angew. Chem Int. Ed. 2007, 119, 5480-5484. [CrossRef]

51. Sakatsuji, W.; Konishi, T.; Miyamoto, Y. Enthalpy Relaxation and Annealing Effect in Polystyrene. Phys. Rev. E Stat. Nonlin Soft Matter Phys. 2013, 88, 012605. [CrossRef] [PubMed]

52. Ediger, M.D.; Angell, C.A.; Nagel, S.R. Supercooled Liquids and Glasses. J. Phys. Chem. 1996, 100, 13200-13212. [CrossRef]

53. Fernandes, A.M.; Rocha, M.A.; Freire, M.G.; Marrucho, I.M.; Coutinho, J.A.P.; Santos, L. Evaluation of Cation-Anion Interaction Strength in Ionic Liquids. J. Phys. Chem. B 2011, 115, 4033-4041. [CrossRef] [PubMed]

54. Kirchner, B. Ionic Liquids from Theoretical Investigations. In Ionic Liquids; Topics in Current, Chemistry; Kirchner, B., Ed.; Springer: Berlin/Heidelberg Germany, 2008; Volume 290, pp. 213-262. [CrossRef] 